\title{
Simulations of high-rate diamond synthesis: Methyl as growth species
}

\author{
D. G. Goodwin \\ Division of Engineering and Applied Science, California Institute of Technology, Pasadena, \\ California 91125
}

(Received 4 March 1991; accepted for publication 15 April 1991)

\begin{abstract}
The results of numerical simulations of two high-rate diamond growth environments (oxygenacctylene torch and dc arcjet) are reported. The calculations account in detail for boundary-layer transport, gas-phase chemistry, and gas-surface chemistry. Diamond growth rates are calculated self-consistently with the gas-phase concentrations, using a recently proposed methyl growth mechanism. The calculated growth rates agree well with the measured values, indicating that this growth mechanism can account for both high- and low-rate diamond growth.
\end{abstract}

Polycrystalline diamond films are now routinely grown using a wide variety of techniques, at rates ranging from less than $1 \mu \mathrm{m} / \mathrm{h}$ to nearly $1 \mathrm{~mm} / \mathrm{h}$. The highest growth rates (typically on the order of $50-100 \mu \mathrm{m} / \mathrm{h}$ ) are obtained in atmospheric-pressure oxygen-acetylene flames ${ }^{1-4}$ and moderate pressure (200 Torr-1 atm) dc arcjet plasmas. ${ }^{5-8}$ It is of considerable interest to determine whether a single mechanism can explain growth in all environments, or whether high- and low-rate chemical vapor deposition (CVD) diamond synthesis techniques differ fundamentally.

Recent experiments in low-pressure hot-filament reactors ${ }^{9,10}$ and flowtubes ${ }^{11,12}$ provide evidence that the methyl radical $\mathrm{CH}_{3}$ is the principal growth species for low-pressure, low-growth-rate conditions. Recently, Harris ${ }^{13}$ has presented a mechanism for growth from $\mathrm{CH}_{3}$ on the (100) surface, and shown that the growth rates predicted by this mechanism for hot-filament conditions $(0.06-0.6 \mu \mathrm{m} / \mathrm{h})$ are similar to those measured.

It has not been clear whether this mechanism, or any methyl mechanism, could account for the high growth rates obtained in oxyacetylene torches and dc arcjets. Several other growth species have been proposed for these environments, including $\mathrm{C}, \mathrm{CH}, \mathrm{C}_{2}$, and $\mathrm{C}_{2} \mathrm{H} .^{3,14,15}$ In this letter, the results of detailed numerical simulations of two high-growth-rate experiments ${ }^{3,8}$ are presented, with the objective of determining whether a methyl growth mechanism can account for the measured growth rates.

The flow of interest here is a hot, axisymmetric gas jet impinging at normal incidence on a water-cooled substrate, as shown in Fig. 1. We confine our attention to the boundary-layer region near the substrate on the axis of symmetry (i.e., at the stagnation point). The exact conservation equations ${ }^{16}$ for mass, radial momentum, energy, and species are solved, together with appropriate boundary conditions, for the boundary layer on the symmetry axis, to yield velocity, temperature, and species concentration profiles. An important feature of these calculations is that a detailed gas-surface chemistry mechanism is included, and the surface site coverages are calculated self-consistently with the gas-phase concentrations. Gas-phase chemistry is also taken into account, considering a total of 161 oxidation and pyrolysis reactions, with rates taken from the literature. ${ }^{17-20}$ The transport properties are all evaluated using the subroutine package of Kee et $a l^{21}$
Near the stagnation point, the velocity field above the boundary layer is governed by a parameter $a$, the stagnation-point velocity gradient parameter. ${ }^{22}$ Here we estimate $a$ as $a \approx 2 \bar{u} / R$, where $\bar{u}$ is the mean axial jet velocity, and $R$ the estimated jet radius at the substrate. The significance of this parameter for the flow field near the substrate is that the boundary layer thickness is given approximately by $\delta_{B L}$ $\sim \sqrt{\mu_{\infty} / \rho_{\infty} a}$, where $\mu_{\infty}$ and $\rho_{\infty}$ are the gas viscosity and density, respectively, outside the boundary layer.

The diamond growth mechanism used is a slightly modified form of the methyl growth mechanism proposed by Harris. ${ }^{13}$ The rate coefficients describing adsorption of $\mathrm{H}$ atoms have been adjusted to yield unity sticking probability in the limit of large site coverage [a factor of two decrease for reactions (b), (e), and ( $g$ ) of Ref. 13]. Harris presents two limiting sets of rate constants, one for a "dilute" case, where the surface is atomically flat and thus surface carbons are bonded to two other carbons, and a "dense" case, where step sites dominate and most surface carbons are bonded to three other carbons. Both cases are considered in the present simulations. To this growth mechanism, 9 reactions describing radical recombination on the surface via $\mathrm{H}$-atom abstraction (e.g., $\mathbf{R}+\mathbf{H H}=\mathbf{R H}+\mathbf{H}^{*}$ ) are added.

We have used our model to simulate two high-growthrate experiments reported in the literature: the oxygenacetylene flame experiments of Matsui et al. ${ }^{3}$ and the $\mathrm{dc}$ arcjet experiments of the group at SRI. ${ }^{8,15}$ While similar studies have been carried out by others, these two are dis-

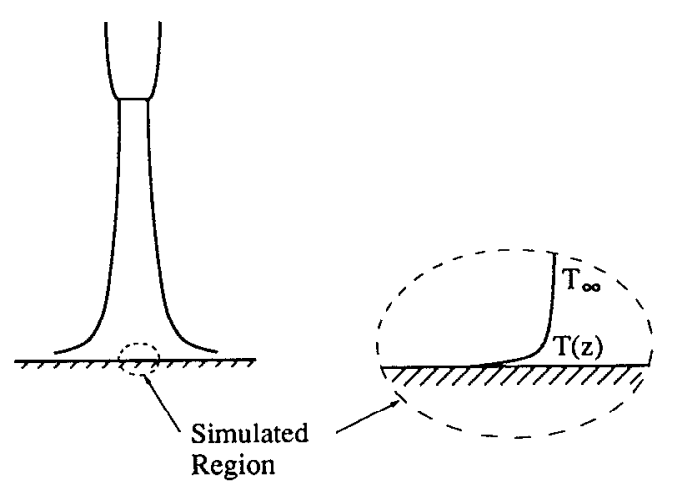

FIG. 1. Relevant flow geometry. The simulations are limited to the stagnation-point boundary layer region. 

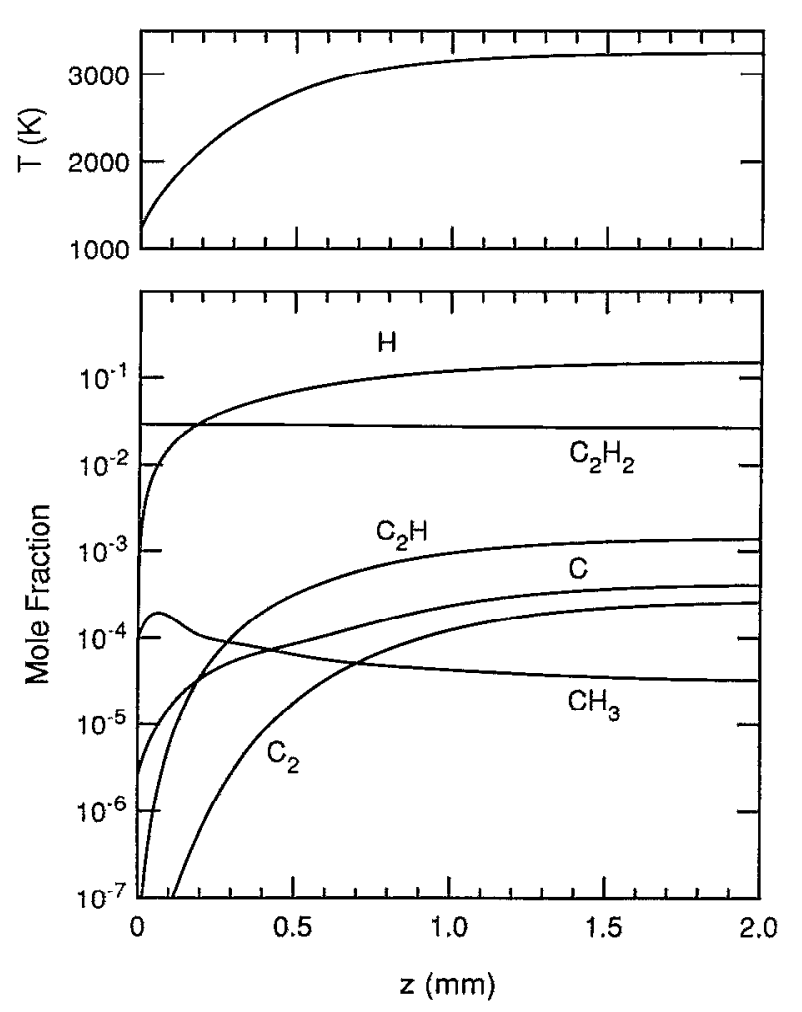

FIG. 2. Temperature and selected species profiles calculated for $\mathrm{C}_{2} \mathrm{H}_{2}$ ' $\mathrm{O}_{2}=1.1$ and a substrate temperature of $1250 \mathrm{~K}$. The surface chemistry is calculated with rate constants for the "dense" case.

tinguished by the relatively complete reporting of experimental conditions (gas flow rates, temperatures, and jet diameters), which makes possible the numerical simulation of the results.

Matsui et $a l^{3}$ show, using laser-induced fluorescence and mass spectrometric techniques, that the gas composition in the acetylene feather region of their flame is consistent with the assumption of chemical equilibrium. Consequently, for the simulations the gas composition outside the boundary layer is assumed to be the equilibrium composition corresponding to the adiabatic flame temperature $T_{a d}$. Based on their reported gas flow rates for the case $\mathrm{C}_{2} \mathrm{H}_{2} / \mathrm{O}_{2}=1.1\left(3.2 \operatorname{sim} \mathrm{C}_{2} \mathrm{H}_{2}, 2.9 \operatorname{sim} \mathrm{O}_{2}\right)$ and jet diameter $(\sim 1 \mathrm{~cm})$, the velocity gradient parameter $a$ is estimated to be approximately $5000 \mathrm{~s}^{-1}$.

The calculated temperature profile and several species profiles are shown in Fig. 2 for the case $\mathrm{C}_{2} \mathrm{H}_{2} / \mathrm{O}_{2}=1.1$. The thermal boundary layer is seen to be approximately 1 $\mathrm{mm}$ thick. A notable feature of these results is the $\mathbf{H}$ atom profile, which drops off sharply near the surface. These results show that the transport of $\mathrm{H}$ to the substrate is diffusion limited, due to the destruction of $\mathrm{H}$ atoms on the surface. The consumption of $\mathrm{H}$ at the surface is an intrinsic part of the diamond growth mechanism, resulting from abstraction of surface-bonded $\mathrm{H}$ by gas-phase $\mathrm{H}$ atoms (activating the surface), and recombination of $\mathrm{H}$ onto surface radical sites [reactions (a) and (b) of Ref. 13]. These two reactions, taken together, describe a mechanism for surface-catalyzed recombination of $\mathrm{H}$ to $\mathrm{H}_{2}$.

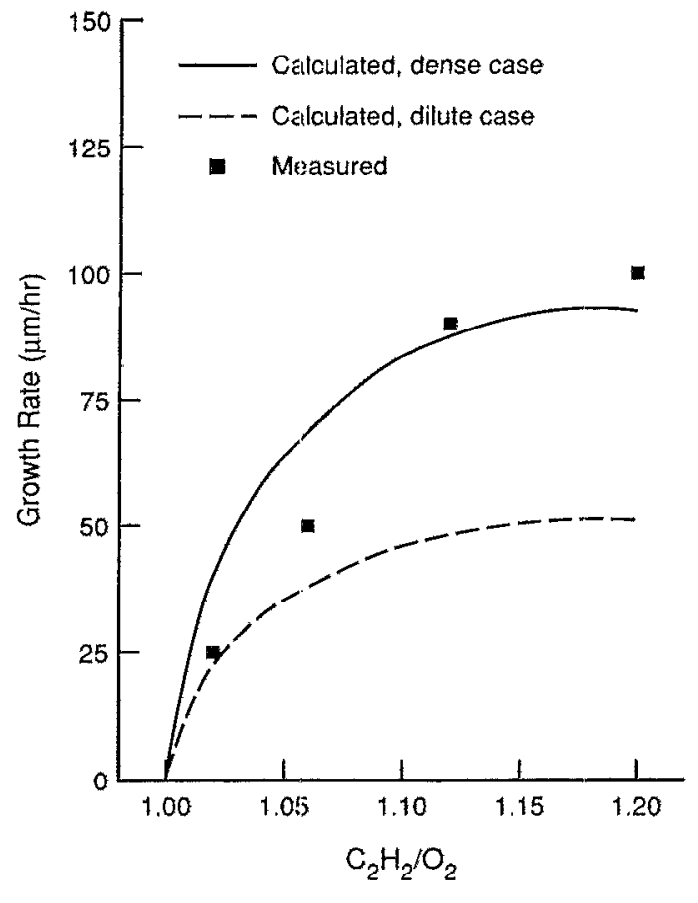

FIG. 3. Comparison of calculated growth rates with those measured by Matsui et al. [Jpn. J. Appl. Phys. 28, 1718 (1989)] as a function of flame stoichiometry.

Methyl is predicted to be the most abundant hydrocarbon radical at the surface. Other radicals which have been proposed as growth species in flame environments are seen to decay sharply near the surface, making a role for these in diamond growth unlikely, with the possible exception of atomic carbon.

The calculated growth rates are compared in Fig. 3 to the growth rates measured by Matsui et al. ${ }^{3}$ for $\mathrm{C}_{2} \mathrm{H}_{2} / \mathrm{O}_{2}$ ratios from 1.0 to 1.2. The results show that this methyl growth mechanism can predict the measured growth rates to within a factor of 2 using either set of rate constants. This is considerably better than expected, considering the significant uncertainties in the surface chemistry, as well as the fact that the mechanism of Harris considers only homoepitaxial growth on (100), while the films are polycrystalline. In addition, the rate predictions are sensitive to both the calculated $\mathrm{H}$ and $\mathrm{CH}_{3}$ concentrations at the surface, which we estimate to be uncertain by about a factor of two or three. In light of this, the agreement shown in Fig. 3 may be to some extent fortuitous. Nevertheless, it is worth noting that there are no adjustable parameters in either the surface mechanism or the gas-phase mechanism.

The same model has been used to simulate the dc arcjet experiments of Stalder and Sharpless ${ }^{8}$ and Raiche et al. ${ }^{15}$ These experiments were carried out at 220 Torr, with a gas composed of $0.5 \% \mathrm{CH}_{4}$ in $\mathrm{H}_{2}$. For this case, the flow time from the anode to the substrate $(8.5 \mu \mathrm{s})$ is too short for chemical equilibrium to be obtained: consequently, we follow here the same procedure used by Raiche et $a l^{15}$ to estimate the plasma composition above the boundary layer: the composition is allowed to evolve for $1.5 \mu \mathrm{s}$ at $5000 \mathrm{~K}$, 


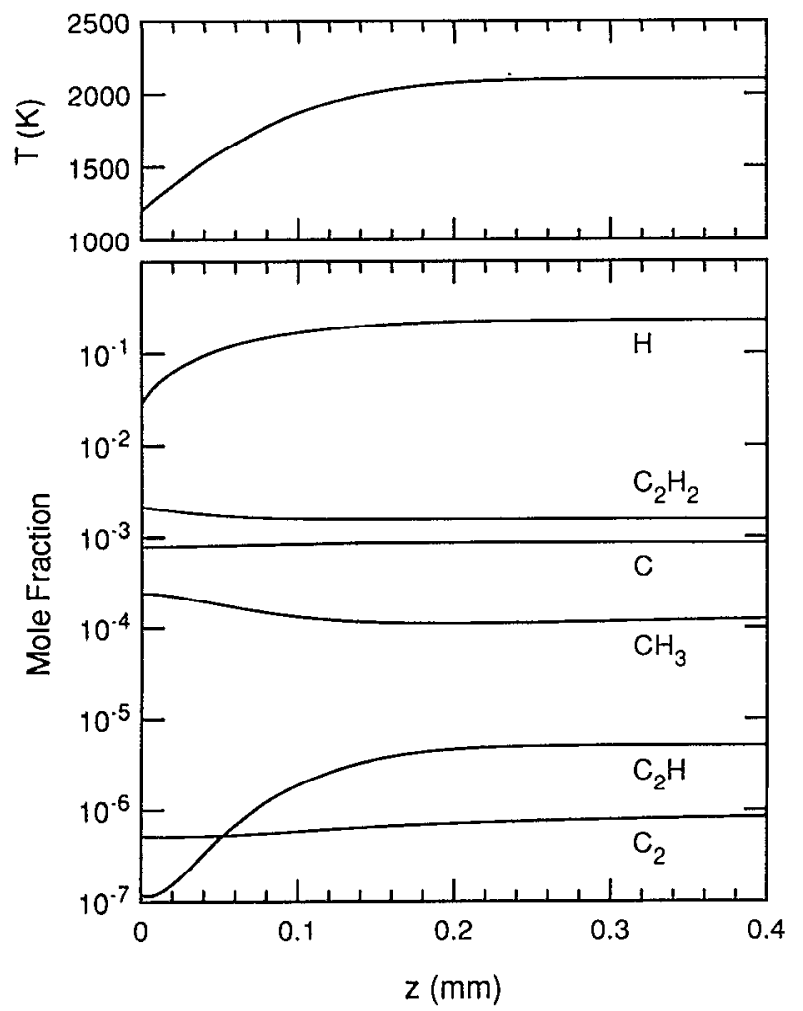

FIG. 4. Temperature and selected species profiles calculated for the SRI dc arcjet conditions. The surface chemistry is calculated with rate constants for the "dense" case.

followed by a linear decrease to the measured gas temperature of $2100 \mathrm{~K}$ at $10 \mu \mathrm{s}$. The $a$ parameter is estimated to be $\approx 10^{6} \mathrm{~s}^{-1}$, and the substrate temperature is taken to be $1200 \mathrm{~K}$.

The predicted temperature and species profiles for this experiment are shown in Fig. 4. For this case, the thermal boundary layer is considerably thinner than in the flame experiment, due to the much higher flow velocity (larger a). For this reason, the effects of chemistry on the concentration profiles are considerably less here than in the flame.

Somewhat surprisingly, atomic carbon is predicted to have a large concentration at the surface. This is a consequence of the large superequilibrium of atomic hydrogen, and the fact that abstraction of a surface hydrogen by $\mathrm{C}$ is uphill by about $10 \mathrm{kcal} / \mathrm{mole}$. Under conditions such as these, $\mathrm{C}$ atoms could conceivably play a role in diamond growth; in the present simulations, however, this possibility is neglected to focus on the question of whether $\mathrm{CH}_{3}$ can explain the measured rates.

The growth rate calculated for this experiment using the Harris methyl mechanism is $118 \mu \mathrm{m} / \mathrm{h}$ for the dense case, and $13 \mu \mathrm{m} / \mathrm{h}$ for the dilute case. The measured rate is reported to be greater than $60 \mu \mathrm{m} / \mathrm{h} .{ }^{8}$

These results indicate that a single methyl mechanism ${ }^{13}$ can explain growth both in low-rate environments, such as hot-filament systems, and high-rate flame and plasma jet environments. While a possible role for other radicals, in particular $\mathrm{C}$ atoms, should not be ruled out, these results show that there is no necessary reason to postulate them as growth species. The question remains why the simple mechanism of Ref. 13 should predict growth rates as well as it does. There are many reasons why it should not, including the large uncertainties in the thermochemistry of the highly crowded (100) surface, and that the experimental films are polycrystalline. Nevertheless, growth rates for (100) and (111) faces are known to be similar, ${ }^{23}$ and so a (100) mechanism may well predict correct polycrystalline rates. The fact that the dense rate constants produce consistently better agreement with experiment than those for the dilute case may indicate that tertiary surface carbons are most common, which suggests that even the (100) surface of CVD diamond is rough on an atomic scale.

The author would like to acknowledge Dr. Stephen Harris for enlightening discussions regarding diamond growth kinetics. This work has been supported, in part, by the Office of Naval Research and the National Science Foundation.

${ }^{1}$ Y. Hirose and M. Mitsuizumi, New Diamond 4, 34 (1988).

${ }^{2}$ L. M. Hanssen, W. A. Carrington, J. E. Butler, and K. A. Snail, Mater. Lett. 7, 289 (1988).

${ }^{3}$ Y. Matsui, A. Yuuki, M. Sahara, and Y. Hirose, Jpn. J. Appl. Phys. 28, 1718 (1989).

${ }^{4}$ Y. Matsui, H. Yabe, and Y. Hirose, Jpn. J. Appl. Phys. 29, 1552 (1990).

${ }^{5}$ N. Koshino, K. Kurihara, M. Kawarada, and K. Sasaki, in Diamond and Diamond-Like Materials Synthesis, edited by G. H. Johnson, A. R. Badzian, and M. W. Geis (Materials Research Society, Pittsburgh, PA, 1988), pp. 95-98.

${ }^{6} \mathrm{~S}$. Matsumoto, in Diamond and Diamond-Like Materials Synthesis, edited by G. H. Johnson, A. R. Badzian, and M. W. Geis (Materials Research Society, Pittsburgh, PA, 1988), pp. 119-122.

${ }^{7}$ N. Ohtake, H. Tokura, Y. Kuriyama, Y. Mashimo, and M. Yoshikawa, Proceedings of the First International Conference on Diamond and Diamond-Like Films, edited by J. P. Dismukes (The Electrochemical Society, Pennington, NJ, 1989), pp. 93-105.

${ }^{8}$ K. R. Stalder and R. L. Sharpless, J. Appl. Phys. 68, 6187 (1990).

${ }^{9}$ C. J. Chu, M. P. D'Evelyn, R. H. Hauge, and J. L. Margrave, J. Mater. Res, 5, 2405 (1990).

${ }^{10}$ C. J. Chu, M. P. D'Evelyn, R. II. ILauge, and J. L. Margrave, J. Appl. Phys. Scheduled for 1 Aug (1991).

${ }^{11}$ L. R. Martin and M. W. Hill, J. Mat. Sci. Lett. 9, 621 (1990).

${ }^{12}$ S. J. Harris and L. R. Martin, J. Mater. Res. 5, 2313 (1990).

${ }^{13}$ S. J. Harris, Appl. Phys. Lett. 56, 2298 (1990).

${ }^{14}$ M. A. Cappelli and P. H. Paul, J. Appl. Phys. 67, 2596 (1990).

${ }^{15}$ G. A. Raiche, G. P. Smith, and J. B. Jeffries, Proceedings of the Second International Conference on the New Diamond Science and Technology, edited by R. Messier and J. T. Glass (Materials Research Society, Pittsburgh, PA, in press).

${ }^{16}$ D. G. Goodwin and G. G. Gavillet, J. Appl. Phys. 68, 6393 (1990).

${ }^{17}$ S. J. Harris, J. Appl. Phys. 65, 3044 (1989).

${ }^{18} \mathrm{~J}$. Warnatz, in Combustion Chemistry, edited by W. C. Gardiner, Jr. (Springer, New York, 1984), pp. 1773-1782.

${ }^{19}$ NIST Chemical Kinetics Database, version 2.0, U.S. Department of Commerce, National Institute of Standards and Technology, Standard Reference Data Program, Gaithersburg, MD, 1990.

${ }^{20}$ J. A. Miller and C. T. Bowman, Prog. Energy Combust. Sci. 15, 287 (1989).

${ }^{21}$ R. J. Kee, G. Dixon-Lewis, J. Warnatz, M. E. Coltrin, and J. A. Miller, Sandia National Laboratories Report SAND86-8246 (1986).

${ }^{22}$ F. M. White, Viscous Fluid Flow (McGraw-Hill, New York, 1974), pp. 596-600.

${ }^{23}$ M. W. Geis, in Diamond, Silicon Carbide and Related Wide Bandgap Semiconductors, edited by J. T. Glass, R. Messier, and N. Fujimori (Materials Research Society, Pittsburgh, PA, 1990), pp. 15-22. 